\title{
Assessing the Primary Causes of Hypertension in Khyber Pakhtunkhwa, Pakistan
}

\author{
Zafar Khan \\ MPhil. Sociology, University of Agriculture Peshawar, Pakistan \\ E-mail: zafarkhanswati87@yahoo.com \\ Mushtaq Ahmad \\ Assitant Professor, University of Agriculture Peshawar, Pakistan \\ E-mail: mushtaqajadoon@yahoo.com
}

Ghufran

MPhil. Pharmacology, Khyber Medical University, Peshawar, Pakistan

E-mail: dr.ghufran2012@gmail.com

Ghulam Nabi (Corresponding author)

MPhil. Endocrinology, Department of Animal Sciences, Laboratory of Reproductive Neuro-endocrinology, Quaid-i-Azam University, Islamabad, Pakistan

Tel: 92-345-811-2741Ｅ-mail: ghulamnabiqau@gmail.com

Asma Hameed

MBBS. Dow Medical University, Karachi, Pakistan

E-mail:asma-khan32@hotmail.com

Received: February 19, 2015 Accepted: March 4, 2015

doi:10.5296/jbls.v6i2.7119 URL: http://dx.doi.org/10.5296/jbls.v6i2.7119 


\section{Abstract}

Hypertension also called a silent killer is a serious problem. The numbers of hypertensive patients are increasing day by day. The present study aim to assess the primary causes of hypertension in Khyber Pakhtunkhwa. Data for the study were collected from 298 hypertensive patients who were admitted or visited to Hayatabad Medical Complex Peshawar as patients. Simple random sampling method was used for selection of the sampled respondents. The results indicate a significant association between hypertension and the level of education $(\mathrm{P}=.000)$. Educated people were found not only having more information about hypertension but also found more conscious about the disease $(\mathrm{P}=.000)$, while no or low level of educated patients were reported not only caring (P.000) the hypertension but also were not consulting doctors $(\mathrm{P}=.000)$. Sampled hypertensive patients were also agreed that regular use of antihypertensive medicines $(\mathrm{P}=.000)$, easy supply of medicines $(\mathrm{P}=.001)$, regular exercise $(\mathrm{P}=.000)$ and regular check-up of blood pressure (P.000) can help maintain blood pressure in normal range while irregularity in taking of medicines $(\mathrm{P}=.000)$ and sedentary life style $(\mathrm{P}=.000)$ contributed to high blood pressure. Dietary habits $(\mathrm{P}=.005)$ such as junk food $(\mathrm{P}=.000)$ and spicy diet (P.000) reported affected the blood pressure. Regarding precautions significant association was found with life style modification $(\mathrm{P}=.000)$, regular check-up of blood pressure $(\mathrm{P}=.000)$, regular exercise $(\mathrm{P}=.036)$, weight reduction $(\mathrm{P}=.001)$, avoid alcohol consumption $(\mathrm{P}=.000)$, stopped smoking $(\mathrm{P}=.000)$ and avoid stress $(\mathrm{P}=.002)$ along with more use of vegetables and fruits $(\mathrm{P}=.001)$. On the other hand hypertension was also associated significantly with the people who have obesity $(\mathrm{P}=.004)$, lake of exercise $\mathrm{P}=.000)$, old people $(\mathrm{P}=.034)$, low socio-economic status $(\mathrm{P}=.000)$, kidney diseases $(\mathrm{P}=.000)$, endocrine diseases $(\mathrm{P}=.000)$, excessive salt intake $(\mathrm{P}=.008)$, low potassium intake $(\mathrm{P}=.010)$ and family history $(\mathrm{P}=.001)$. Individually and psychologically the hypertension can also be due to alcohol intake $(\mathrm{P}=.000)$, cigarette smoking $(\mathrm{P}=.000)$, sedentary life style $(\mathrm{P}=.000)$, lake of exercise $(\mathrm{P}=.000)$, lake of knowledge about the signs, symptoms of hypertension $(\mathrm{P}=.000)$, its causes $(\mathrm{P}=.000)$, and precautions $(\mathrm{P}=.000)$. Study recommends that in order to control hypertension, a special attention is needed to follow the precautions about hypertension, diet plan, regular check-up of blood pressure, awareness about the disease and avoid stress.

Keywords: Hypertension, Blood pressure, Antihypertensive medicines, Dietary habits, Obesity

\section{Introduction}

Hypertension is a medical condition when the systolic blood pressure of a person is consistently $140 \mathrm{~mm} \mathrm{Hg}$ (millimeters of mercury) or greater and his diastolic blood pressure is consistently $90 \mathrm{~mm} \mathrm{Hg}$ or greater (Guyton and Hall, 2006). It is one of the most important risk factor among the five leading risks factors for mortality in the world. Fifty one percent of the death occurs due to cerebrovascular accident and forty five percent of death occurs due you to heart attack. These both are attributed to hypertension (World Health Organization Report, 2009). There are various causes of hypertension such as obesity, old age, lack of exercise (Danish, 2006), low income, low education (Cyril and Neil, 2008), renal vascular disease, cushing syndrome, use of non-steroidal anti-inflammatory drugs and oral contraceptives 
(estrogens) (Danish, 2006). Similarly stress, low self-esteem, depression (Oparil, 2006), heavy alcohol intake and cigarette smoking (Cyril and Neil, 2008) and excessive salt intake (Danish, 2006) increases blood pressure. The prevalence of the hypertension is high in the developed countries but also in developing countries the ratio is increasing day by day (Zafar, 2008). Hypertension is estimated to responsible for 12. 5 percent of death in men and 15.1 percent in women (World Health Organization, 2002). It is a serious problem and called silent killer, which equally affect the heart, brain, kidneys, and peripheral vessels of the individual with hypertension (Shiraz, 2013). At the present moment globally approximately one billion people are hypertensive which has high blood pressure greater than 140/90mm Hg (Sarafidis et al., 2008). It is estimated that by the year 2025, 1.56 billion of the world's population will be suffering from hypertension (Zafar, 2008). Due to this high prevalence, associate morbidity, mortality and huge economic burden, hypertension has become one of the greatest challenges of the modern era (Rizwan, 2008). Comprehensive strategies should plan for reduction in complication, mortality and morbidity due to high blood pressure. It includes preventive strategies, increased awareness, early diagnose, adequate and long term treatment, strict control of blood pressure, life style modification, control obesity, plan diet for hypertension, low sodium intake, regular exercise, low consumption of alcohol and to stop the use of tobacco. After these measurements the medicines plays its role (Almas, 2008). Hypertension is a multi-factorial disorder but any single risk factor can contribute to overall increase in blood pressure. For strict control of blood pressure awareness and compliance to medication are important. Knowledge on hypertension is not only necessary among the patients but should also be conveyed to the general population in Pakistan, because the family members are actively involved in the patient care. It is important for all to realize the seriousness of hypertension as a disease (Zafar, 2008).

The national Health survey of Pakistan (NHSP) reported that 18 percent of adults greater than the age of 15 years and 40 percent of adults greater than the age of 45 years are suffered from hypertension (Zafar, 2008). The prevalence of hypertension is about ten percent in the general population of Pakistan and it is increased to twenty percent of population over the age of 15 years and it is increase to every third person over the age of 45 years which is greater than the rest of population of the world (Faruqui, 1997). Majority of the people does not have access to health facilities in Pakistan. Only thirty percent of the world population have available the medical facilities in a range of 5 kilometers, but the situation is more serious in Pakistan particularly to the people in mountain and hills (World Health Organization, 2006). Hypertension affects about 40 percent adults of age 18 years and above. One third individuals over the age of 45 years is hypertensive in Pakistan. There are estimated 20 million hypertensive patients in the country. Where 18 percent of the total 20 million hypertensive take medicines where as 97 percent of the patient are unable to control it. Overall urban Pakistani population has higher prevalence of high Blood pressure i.e. 21 percent then rural Pakistani population which is 16 percent (World Health Organization Report, 2009).

The present study is therefore designed to (1) find out the perception of hypertensive patients about the disease in the study area. (2) To examine the primary causes that result hypertension among the sampled population. (3) To measure the association between the 


\section{IIMacrothink}

hypertension and causes of hypertension and (4) to suggest recommendations on the basis of the study findings.

\section{Materials and Methods}

\subsection{Universe of the Study}

This study was conducted in Hayat Abad Medical Complex (HMC) Hospital of Khyber Pakhtunkhwa, Pakistan.

\subsection{Sampling Procedure and Sample Size}

All the patients in Hayatabad Medical Complex who had hypertension, having the age of 20 to 50 years were the respondents of the study. They were included both admitted and outdoor patients. A total of 298 patients were recruited in the study.

\subsection{Methods of Data Collection}

Interview schedule method was used for data collection. It consisted of 84 questions. These questions were designed on the basis of research objectives and finalized by making necessary changes pointed out in pilot survey.

\subsection{Data Analysis}

The data collected was analyzed by using software, statistical package for social sciences (SPSS). The data were categories and presented in the form of percentages in frequencies. Fisher exect and Chi square tests were also used to test the validity in association between the various variables.

\section{Results and Discussion}

\subsection{Age of the Sampled Respondents}

The age of study participants are summarized in Table 1

Table 1. Age of the sampled respondent

\begin{tabular}{|l|l|l|l|}
\hline Sr. No. & Age Group & No. & $\%$ \\
\hline 1. & $20-30$ years & 56 & 18.8 \\
\hline 2. & $31-40$ years & 73 & 24.5 \\
\hline 3. & $41-50$ years & 169 & 56.7 \\
\hline 4. & Total & 298 & 100 \\
\hline
\end{tabular}

\subsection{Sex of the Sampled Respondents}

The sex of the sample respondents are summarized in Table 2 
Table 2. Sex of the sample respondents

\begin{tabular}{|l|l|c|c|}
\hline Sr.No. & Sex of the respondents & No. & $\%$ \\
\hline 1. & Male & 172 & 57.7 \\
\hline 2. & Female & 126 & 42.3 \\
\hline 3. & Total & 298 & 100 \\
\hline
\end{tabular}

\section{3., Educational Status of the Sampled Respondents}

The educational status of sampled respondents are summarized in Table 3

Table 3. Educational status of sampled respondents

\begin{tabular}{|l|l|l|l|}
\hline Sr.No. & Educational status & No. & $\%$ \\
\hline 1. & Illiterate & 140 & 47 \\
\hline 2. & Primary to middle & 47 & 15.8 \\
\hline 3. & Matriculation & 43 & 14.4 \\
\hline 4. & Intermediate \& above & 68 & 22.8 \\
\hline 5. & Total & 298 & 100 \\
\hline
\end{tabular}

\section{4., Blood Pressure (Systolic \& Diastolic Blood Pressure) of Sampled Respondents}

Both systolic and diastolic blood pressure of sampled respondents are summarized in Table 4

Table 4. Systolic and diastolic blood pressure of sampled respondents

\begin{tabular}{|c|c|c|c|}
\hline Sr.No. & Blood Pressure Types & No. & $\%$ \\
\hline \multirow{4}{*}{1.} & Systolic Blood Pressure (in mmHg millimeter of mercury) \\
\cline { 2 - 4 } & $140-150$ & 174 & 58.4 \\
\cline { 2 - 4 } & $151-160$ & 92 & 30.9 \\
\cline { 2 - 4 } & $161-170$ & 30 & 10.1 \\
\cline { 2 - 4 } & $171-180$ & 2 & 0.7 \\
\hline \multirow{4}{*}{2.} & Total & 298 & 100 \\
\cline { 2 - 4 } & Diastolic Blood Pressure (in mmHg millimeter of mercury) \\
\cline { 2 - 4 } & $90-95$ & 150 & 50.3 \\
\cline { 2 - 4 } & $96-100$ & 122 & 40.9 \\
\cline { 2 - 4 } & $101-105$ & 23 & 7.7 \\
\cline { 2 - 4 } & $106-110$ & 3 & 1 \\
\hline
\end{tabular}

\section{5., The Duration of the Disease of the Sampled Respondents}

Duration of the disease of the sampled respondents are summarized in Table 5

Table 5. Duration of the disease of the sampled respondents

\begin{tabular}{|l|l|l|l|}
\hline Sr.No. & Duration of disease in year & No. & $\%$ \\
\hline 1. & 1 year & 50 & 16.8 \\
\hline 2. & 2 years & 64 & 21.5 \\
\hline
\end{tabular}




\begin{tabular}{|l|l|l|l|}
\hline 3. & 3 years & 47 & 15.8 \\
\hline 4. & 4 years & 23 & 7.7 \\
\hline 5. & 5 years & 39 & 13.1 \\
\hline 6. & 6 years & 10 & 3.4 \\
\hline 7. & 7 years & 12 & 4 \\
\hline 8. & 8 years & 9 & 3 \\
\hline 9. & 9 years & 2 & 0.7 \\
\hline 10. & 10 years & 42 & 14.1 \\
\hline 11. & Total & 298 & 100 \\
\hline
\end{tabular}

\subsection{Regular Check-up of Blood Pressure by Sampled Respondents}

Regular check-up of blood pressure by sampled respondents are summarized in Table 6

Table 6. Regular check-up of blood pressure by sampled respondents

\begin{tabular}{|l|l|l|l|}
\hline Sr.No. & Checkup by doctor & No. & $\%$ \\
\hline \multirow{2}{*}{1.} & Yes & 148 & 49.7 \\
\cline { 2 - 4 } & No & 150 & 50.3 \\
\hline 2. & If No, Reasons & 56 & 18.8 \\
\hline & No checkup facility & 37 & 12.4 \\
\hline & No time/busy life & 23 & 7.7 \\
\hline & No awareness of regular checkup & 34 & 11.4 \\
\hline & No money/financial problems & 298 & 100 \\
\hline & Total & \multicolumn{2}{|l}{} \\
\hline
\end{tabular}

\subsection{Hypertension}

Our data suggests that 90 percent of sampled respondents had described hypertension a serious problem now-a-days, while 38, 43, 66, 38, 49 and 82 percent replied that hypertension is a silent killer, people are conscious about hypertension, prevalence of hypertension is very high now-a days, hypertension is a major cause of mortality, hypertension is the greatest challenge to modern societies and people do not care about hypertension respectively. Contrary to this a 25 percent of the sampled respondents said that hypertension is not a silent killer and 23, 19 and 13 percent said that people are not conscious about hypertension, hypertension is not a major cause of mortality and people do care about hypertension respectively. Another 8 percent of sampled respondents did not know even that hypertension is a serious problem now-a-days, whereas 37, 34, 29, 43, 40 and 13 percent of the sampled respondents also did not know that hypertension is a silent killer, people are conscious about hypertension, prevalence of hypertension is very high now-a days, hypertension is a major cause of mortality, hypertension is the greatest challenge to modern societies and people do not care about hypertension respectively.

The results are supported by the findings of Shiraz (2013) and Zafar and Rizwan (2008). They said that hypertension is silent killer and the prevalence is very high now-a-days. 


\subsection{Education of the Respondents}

In our findings, 73.5 percent of the sampled respondents answered that more the level of education more the information about of the disease, another 72, 68, 61 and 49 percent of the sampled respondents said that more the level of education more the consciousness about the precautions of the disease, no or low educated patients do not consult to doctor regarding their hypertension, no or low educated patients do not care hypertension and high educational level of individuals cause decline in hypertension respectively. Another 15 and 14 percent of the sampled respondents denied about high educational levels of individuals cause hypertension decline and no or low educated patients do not care hypertension respectively. Another 36 percent of the sampled respondents were found that not knowing about high educational level of individuals cause hypertension decline whereas the others 25, 24, 23 and 21 percent of the sampled respondents also did not know about no or low educated patients do not care hypertension, no or low educated patients do not consult to doctor regarding their hypertension, more the level of education more the consciousness about the precautions of the disease and more the level of education more the information about of the disease respectively.

Our findings are supported by Dodani et al., 2004, Jeffery et al., 2007; Deborah et al., 2008 and Bendary et al., 2013 who found that education is a strong factor affecting high blood pressure.

\subsection{Use of Anti-Hypertensive Medicines and Exercise}

We investigated that 96 percent of the sampled respondents answered that regular use of anti-hypertensive medicines maintaining the blood pressure normal while the others $94,92,83$, 68 and 50 reported that easy supply of medicines helps to maintain the blood pressure in normal range, irregularity in taking of medicines can leads to hypertension, regular checkup of blood pressure helps in maintaining the blood pressure in normal range, regular exercise maintains the blood pressure in the normal range and sedentary life style contributes to high blood pressure respectively. Contrary to this 14 and 8 percent of the sampled respondents did not agree about the sedentary life style that contributes to high blood pressure and the regular exercise that maintains the blood pressure in the normal range respectively. A part from this 36, 24 and 14 percent of the sampled respondents did not know that sedentary life style contributes to high blood pressure, regular exercise and regular checkup of blood pressure helps in maintaining the blood pressure in normal range respectively.

Our results are supported by Siddiqui, 2005, Deborah et al., 2008; Grotto et al., 2008 and David et al., 2009 who observed that use of antihypertensive medicines and exercise play a very important role in the controlling of high blood pressure.

\subsection{Diet Habits}

Our findings shows that 94 percent of the sampled respondents had given their opinion that salt free diet is useful in hypertension and others 87, 68, 58, 24 and 18 percent said that dietary habits strongly effect hypertension, they have diet plan regarding to the control of hypertension and they use fat free diet regularly, use spicy diet regularly and use junk food regular respectively. Another 69 percent of the sampled respondents did not use junk food and spicy diet regularly, whereas 37 percent of the sampled respondents used fat free diet, another 30 
percent of the sampled respondents had not diet plan regarding hypertension while 5 percent denied about the salt free diet that is useful in hypertension and 4.4 percent of the sampled respondents denied the dietary habits that strongly effect hypertension. Apart from this 13 percent of the sampled respondents did not know about the junk food, whereas 8.4 percent did not know that dietary habits strongly affect hypertension, while 7.7, 5, 2.7 and 1 percent of the sampled respondents did not know about the use of spicy, fat free diet, diet plan and salt free diet is useful in hypertension respectively.

Thus our results are in agreement with the results of Christopher et al., 2008 and Akhtar, 2011 who found a strong association between hypertension and diet.

\subsection{Precautions about Hypertension}

In our study 81.5 and 80.5 percent of the sampled respondents had restricted salt and started using vegetables and fruits, while $74.8,72.5,66.8,66.4,60,59,56$ and 53 percent tried to control blood pressure by avoiding alcohol consumption, stopped smoking, changed diet habits, modified life style, regular check-up of blood pressure, regular exercise, reduced their weight and avoided tension respectively. At the same time 39, 38.3, 38, 37.9, 30 and 26 percent of the sampled respondents did not take the precautions like regular check-up their blood pressure, regular exercise, reduced their weight, avoided stress, changed their diet habits and modified their life style respectively. On the other hand 14, 13 and 9 percent of the sampled respondents did not know about the precautions of hypertension likes alcohol consumption, smoking and stress respectively.

The results are supported by the findings of Peter and Nilson, 2009 and Prin et al., 2012 who found that precautions can help in controlling hypertension.

\subsection{Social Causes and Biological Causes}

Our analysis shows that 92 percent of the sampled respondents had answered that excessive salt intake increase the blood pressure whereas a 85, 83, 79, 78, 76, 75, 74, 70 and 65 percent of the sampled respondents had given their opinion that family history has relationship with hypertension, they had a family history of hypertension, old people are more prone to develop high blood pressure, their mothers are suffering from the disease, obese people are more prone to develop high blood pressure, low socio-economic status people have high blood pressure, lake of exercise is one of the factor of high blood pressure, their fathers are suffering from the disease and children of hypertensive patients are more prone to develop hypertension respectively.

On the other hand 13, 18 and 23 percent were found denied about the statements that people with kidney disease have hypertension, low potassium intake increase in blood pressure and fathers are suffering from the disease respectively, while another 77, 73 and 71 percent did not know about regarding that endocrine diseases are responsible for developing hypertension ,non-steroidal anti-inflammatory drugs contributes to high blood pressure along with oral contraceptive drugs are contributes to high blood pressure respectively.

Results as a whole reveal a strong association between the social causes and biological causes 
with hypertension. The results are supported by the findings of the Julia, 2006, Danish, 2006 and Hujova and Rustakova, 2013. They found that socio economic status and biological causes are the most important factors that cause hypertension.

\subsection{Psychological and Individual Level Causes}

In our study major psychological and individual level causes regarding hypertension includes stress and anxiety 95 percent, signs and symptom 73 percent, lake of exercise 71 percent, low self-esteem and low feeling 68 percent, knowledge about the disease 65 percent, precautions of the disease 64 percent, cigarette smoking 63 percent, heavy alcohol intake 59 percent and sedentary life style can contribute to high blood pressure 53 percent. On the other hand 51, 28, 27 , and 22 percent of the sampled respondents stated no regarding the causes of the disease, the precautions of the disease, knowledge about the disease and about the sign and symptoms of the disease respectively, while 43, 36, 34, 26 and 23 percent of the sampled respondents reported that they did not know about the statements that sedentary life style can contribute to high blood pressure, heavy alcohol intake may cause high blood pressure, cigarette smoking is one of the important causes of high blood pressure, low self-esteem and low feeling result in high blood pressure and lake of exercise may contribute to high blood pressure respectively.

Similar findings were also reported by Dawn et al., 2000; Siddiqui, 2005; Itamar et al., 2007 and Prin et al., 2012 who observed that psychological and individual level causes are the factors that cause high blood pressure.

\subsection{Education of the Sampled Respondents and Hypertension}

Chi-square results at education level of the sampled respondents showed a significant association between the hypertension and more the level of education, more the information about the disease $(\mathrm{P}=.000)$, more the level of education, more the consciousness about the precautions of the disease $(\mathrm{P}=.000)$, high educational level of individuals cause hypertension decline $(\mathrm{P}=.000)$, no or low educated patients do not care of hypertension $(\mathrm{P}=.000)$ and no or low educated patients do not consult to doctor regarding their hypertension $(\mathrm{P}=.000)$.

The results having similar findings as by Dodani et al., 2004; Jeffery et al., 2007; Deborah et al., 2008; and Bendarly et al., 2013 found that education is a strong factor that affect high blood pressure.

\subsection{Use of Anti-Hypertensive Medicines and Exercise in Hypertension}

There was a significant association between hypertension and regular use of antihypertensive medicines maintaining the blood pressure normal $(\mathrm{P}=.000)$, easy supply of medicines helps to maintain the blood pressure in normal range $(\mathrm{P}=.001)$, irregularity in taking of medicines can leads to hypertension $(\mathrm{P}=.000)$ whereas regular exercise maintains the blood pressure in the normal range $(\mathrm{P}=.000)$, sedentary life style also contributes to high blood pressure $(\mathrm{P}=.000)$ and regular checkup of blood pressure helps in maintaining the blood pressure in normal range (P.000).

Our results are parallel with the results of by Coto et al., 1987; Debora et al., 2008; Grotto et al., 2008 and David et al., 2009 who reported that the use of antihypertensive medicines and 
exercise play a very important role in the controlling of high blood pressure.

\subsection{Precautions and Hypertension}

Precautions regarding hypertension play a very important role in controlling of hypertension because precaution is better than cure. A significant association between hypertension and life style modification $(\mathrm{P}=.000)$, regular check-up of blood pressure $(\mathrm{P}=.000)$, regular exercise $(\mathrm{P}=.036)$, diet habits $(\mathrm{P}=.023)$, weight reduction $(\mathrm{P}=.001)$, avoid alcohol consumption $(\mathrm{P}=.000)$, stopped smoking $(\mathrm{P}=.000)$, avoid stress $(\mathrm{P}=.002)$ and the use of vegetables and fruits $(\mathrm{P}=.001)$. The variable which is found insignificant is salt restriction $(\mathrm{P}=.521)$.

Our results are in favor of Peter and Nilson, 2009 and Prin et al., 2012 who reported that certain precautions can help in the controlling of hypertension.

\subsection{Social and Biological Causes of Hypertension}

Social and biological factors also become the majors of hypertension. A significant association between the hypertension and the obese people $(\mathrm{P}=.004)$, lake of exercise $(\mathrm{P}=.000)$, old people $(\mathrm{P}=.034)$, low socio-economic status $(\mathrm{P}=.000)$, kidney diseases $(\mathrm{P}=.000)$, children of hypertensive patients $(\mathrm{P}=.076)$, endocrine diseases $(\mathrm{P}=.000)$, non-steroidal anti-inflammatory drugs $(\mathrm{P}=.000)$, oral contraceptive drugs $(\mathrm{P}=.010)$, excessive salt intake $(\mathrm{P}=.008)$, low potassium intake $(\mathrm{P}=.010)$, family history $(\mathrm{P}=.001)$, father history $(\mathrm{P}=.000)$ and mother history $(\mathrm{P}=.022)$.

The results are supported by the findings of the Julia, 2006, Danish; 2006 and Hujova and Rustakova, 2013. They found that socio economic status and biological causes are the most important factors that cause hypertension.

\subsection{Psychological and Individual Level Causes of Hypertension}

Psychological and individual level causes may contribute to high blood pressure. A significant association between hypertension and the heavy alcohol intake $(\mathrm{P}=.000)$, cigarette smoking $(\mathrm{P}=.000)$, sedentary life style $(\mathrm{P}=.000)$, lake of exercise $(\mathrm{P}=.000)$, knowledge about the disease $(\mathrm{P}=.000)$, knowledge about the sign and symptoms of the disease $(\mathrm{P}=.000)$, knowledge about the causes of the disease $(\mathrm{P}=.000)$ and knowledge about the precautions of the disease $(\mathrm{P}=.000)$. The variables that found insignificant includes stress and anxiety $(\mathrm{P}=.165)$ and low self-esteem and low feeling $(\mathrm{P}=.171)$.

Similar findings were also reported by Dawn et al., 2000; Siddiqui, 2005; Itamar et al., 2007 and Prin et al., 2012 who observed that psychological and individual level causes are the factors that cause high blood pressure.

\section{Conclusion}

Hypertension is a major health problem worldwide and it affects both males and females. The prevalence of hypertension is very high and this ratio is increasing day by day in the whole world. Many factors contribute to this phenomenon. The most important among all is education where people having more the level of education, more the information about the disease and consciousness about the precautions of the disease. The role of antihypertensive medicines and 
exercise are highly important. The regular use of anti-hypertensive medicines, easy supply of medicines and exercise reported helps maintain the blood pressure in normal range. Dietary habits strongly affect hypertension. Diet plan regarding hypertension maintain the blood pressure in normal range. Precautions regarding hypertension also played a very important role in controlling of hypertension like life style modification, regular checkup of blood pressure, regular exercise, change of diet habits, weight reduction, avoid alcohol consumption, stopped smoking, avoid stress, the use of vegetables and fruits and salt restriction. Social and biological causes also found contributed to high blood pressure which includes obese people, lake of exercise, old people, low socio-economic status, kidney diseases, children of hypertensive patients, endocrine diseases, non-steroidal anti-inflammatory drugs, oral contraceptive drugs, excessive salt intake, low potassium intake and family history. A numbers of factors at individual level also found contributed to hypertension which includes heavy alcohol intake, cigarette smoking, sedentary life style, lake of exercise, knowledge about the disease signs and symptoms, the causes and the precautions of the disease.

\section{References}

Akhtar. (2011). Hypertension and Exercise. Journal of Pak Med, 45.

Almas, A. Naheed, H. Rizwan, S., \& Seema, D. (2008). Hypertension and its socioeconomics determents among Gypsy population aged 30 years and above. J. Allama Iqbal Med Coll. 5(1), 7-12.

Benderly, M. Hain, M. Boy, KO. Gold, V., \& Bourt, V. (2013). Socioeconomic status indicators and incidence of Heart failure among men and women with coronary heart diseases. Card Fail. 19(2), 117-24. http://dx.doi.org/10.1016/j.cardfail.2013.01.002

Christopher, M. Bryanc. \& Laura, P. (2008). The effect of socioeconomic status on food availability and cost of the dietary approach to stop hypertension (DASH) dietary Pattern. Journal of Clinical hypertension, 10(8), 603-611. http://dx.doi.org/10.1111/j.1751-7176.2008.08199.x

Coto, A. Lucariello, M. Cocozza, U. oliviero. \& L, cacciatore. (1987). Socioeconomic status and hypertension in children of two state school .European journal of epidemiology, 3, 288 -294. http://dx.doi.org/10.1007/BF00149738

Cyril, A. keele. \& Neil, E. (2008). Internal medicines. $19^{\text {th }}$ edition. Prentice publication: 156.

Danish, I. (2006). Medical diagnosis and its management. $9^{\text {th }}$ edition. Johor publication: 795.

David, C. Robert, J. Glynn, P. M. et al. (2009). Socioeconomic status, blood pressure progression and incident hypertension in a prospective Cohort of female health professionals. Euro Heart J, 30(11), 1378-1384. http://dx.doi.org/10.1093/eurheartj/ehp072

Dawn, K. Wilson, W. Kliewer. \& Laura, P. (2000). Socio economic status and blood pressure reactivity in healthy black adolescent: American heart association, 35, 296-500.

Deborah, M. Morion, W., \& Sharan, B. (2008). Wyatt: Does socioeconomic status effect the blood pressure goal achievement. Current hypertension report. 10(5), 390-397. 
http://dx.doi.org/10.1007/s11906-008-0073-3

Dodani, S. Mistry, R. Khwaja, A. Farooqi, N., \& Qureshi, R. (2004). Prevalence and awareness of risk factors and behaviors of coronary heart disease in an urban population of Karachi: Public health (oxf), 26(3), 245-9. http://dx.doi.org/10.1093/pubmed/fdh154

Faruqui. Azhar. (1997). The prevalence of hypertension in Pakistan. Pakistan Heart Journal, 30, 3-4.

Grotto, I. Huerta, M., \& Sharabi. Y. (2008). Hypertension and socioeconomic status. Curr opin cardiol. 23(4), 335-9. http://dx.doi.org/10.1097/HCO.0b013e3283021c70

Guyton and Hall. (2006). Medical Physiology. 12 ${ }^{\text {th }}$ edition. Long man Inc. New York: 220

Hujova, Z. Rostakova, K. (2013). Several anthropometric predictions of cardiovascular diseases in central Slovakian adults. Bratist Lek listy. 114(1), 31-5.

Itamar, G. Michal, H. Ehud, G., \& Yehonatan, S. (2007). Relative impact of socioeconomic status on Blood pressure: American Journal of hypertension, (20), 1140-1145.

Jeffrey, D. Morenoft, B. B, Hansen. James. S. House., David. R. Williams., George. A. Kaplan \& Haslyn. E. Hunle. 2007: The role of neighborhood in social disparities in hypertension: hypertension. 07, 07-614.

Julia, M. Mran,, HA. Dlemarre. Surjone, A. (2006). The influence ofsocioeconomic status on blood pressure of Indonesia prepubortal children. Human hypertension, 20, 546-548. http://dx.doi.org/10.1038/sj.jhh.1002028

Peter, M. Nilsson. (2009). Adverse social factors can predict hypertension but how. European Heart Journal, 30, 1305-1306. http://dx.doi.org/10.1093/eurheartj/ehp131

Prin, V. Kit, M. Wood, Ward. Supachai, T. Bunlue, H. Wichai. Ackplakorn., Sukit. Yamwong \& Piyamlr S. (2012). Long term effect of socioeconomic status on incident hypertension and progression of blood pressure. Journal of Hypertension. 30, 1347-1353 http://dx.doi.org/10.1097/HJH.0b013e32835465ca

Sarafidis, P. A., \& Chen, SC. (2008). Hypertension awareness, treatment and control in chronic kidney diseases. Am J Med, 121(4), 332-340. http://dx.doi.org/10.1016/j.amjmed.2007.11.025

Siddiqui, H. Qudsia, A. Amir, O. Javid, U. et al. (2005). Risk factors assessment for Hypertension in a squatter settlement of Karachi. PMA, 55, 390-396.

Shiraz. Fukuday. (2013). Association of household expenditure and marital statuswith cardiovascular risk factors in Japan adults. Epidemiology, 23(1), 21-7. http://dx.doi.org/10.2188/jea.JE20120021

WHO. World Health Statistic. 2009. Geneva. World Health Organization: 2009

World Health Organization. 2006. Promoting Health life: Geneva. 


\section{Macrothink}

World Health organization. 2002. Reducing Risks promoting Health life. Geneva.

Zafar, N. (2008).The prevalence of Hypertension. National Health survey of Pakistan: 711.

\section{Copyright Disclaimer}

Copyright for this article is retained by the author(s), with first publication rights granted to the journal.

This is an open-access article distributed under the terms and conditions of the Creative Commons Attribution license (http://creativecommons.org/licenses/by/3.0/). 